Design We used the CHAMPS-DK data, which includes prospectively collected weekly activity and pain data using SMStexting in Danish schoolchildren.

Setting Recreational children's sports.

Participants Parents of 1152 schoolchildren aged 5-10 in Svendborg, Denmark provided information on their child's activity and pain during 5.5 years of follow-up.

Interventions/Assessment of Risk Factors We measured the coupled ACRatio using activity in the index week (week of new onset pain) divided by average activity in the index and past 3 weeks (total 4 weeks) and the uncoupled ACRatio using activity in the week before the index week divided by average of the 4 weeks before the index week.

Main Outcome Measurements Development of new onset pain. Results The total incidence rate of new onset pain was 2 events per person-year. Coupled ACRatios ranged from 0 to 3.20 (mean 1.00) and uncoupled ACRatios ranged from 0 to 9.33 (mean 1.03). The risk ratio for new onset pain using the coupled ACRatio was $1.26[1.18,1.36]$ for each unit increase in ACRatio. The risk ratio using the uncoupled ACRatio was 1.21 [1.16, 1.27]. There was no U-shaped curve, unlike what has previously been observed in injury studies in adults (Figure 1).

Conclusion The risk of new onset pain in children increases relatively linearly with increases in the coupled and uncoupled ACRatio.

\section{THE ACUTE:CHRONIC WORKLOAD RATIO: WHY ONE SIZE DOES NOT FIT ALL}

${ }^{1}$ Stephen West, ${ }^{1}$ Sean Williams, ${ }^{1}$ Dario Cazzola, ${ }^{2}$ Matthew Cross, ${ }^{3}$ Simon Kemp, 1,3 Keith Stokes. 'University of Bath, Bath, UK; ${ }^{2}$ Premier Rugby Limited, London, UK; ${ }^{3}$ Rugby Football Union, London, UK

\subsection{6/bjsports-2021-IOC.111}

Background The acute: chronic workload ratio (ACWR) is a widely adopted training load aggregation tool to manage injury risk in sport. Recently, methodological concerns have been raised regarding this approach.

Objective To establish best-fit calculation methods for the ACWR when assessing injury risk, and to assess reproducibility of methods between professional Rugby Union teams playing in the same league.

Design Observational cohort study.

Setting Thirteen professional rugby clubs over two seasons.

Patients (or Participants) During two seasons, 433 and 569 players were recruited, meaning 1002 player seasons from 696 unique players.

Interventions (or Assessment of Risk Factors) Calculation methods: rolling averages(RA) versus exponentially-weighted moving averages (EWMA), coupled versus uncoupled, acute time windows (3-9 day), and chronic time windows (14-35 day).

Main Outcome Measurements Akaike Information Criterion (AIC) and Area Under the Curve (AUC) of model fit to injury risk.

Results 129,448 training load values were collected and aggregated into ACWR values to assess and compare their model fit to 1718 recorded injuries. In the 13 clubs there were 8 different 'best fit' ACWR calculations according to AIC score, with 3-day acute loads, 14-day chronic loads, EWMA and coupled approaches being the most common 'best fit' models. When the data was pooled, an EWMA, coupled 3:14 day
ACWR provided the best fit; this finding was supported using AUC. Irrespective of the averaging or coupling method used, there was very little support for the commonly cited 7:28 day ACWR values.

Conclusions The commonly described 7:28 day average ACWR value may not be the most appropriate in a rugby setting, with 3:14 day EWMA coupled ACWRs providing better model fits. In addition, the best-fitting ACWR is highly variable across a somewhat homogenous set of clubs. Therefore, teams wishing to use ACWRs should model their own data to identify the version that is most appropriate for their setting, while the limitations of this metric should be understood when interpreting the data produced.

\section{ANTIOXIDANT BLOOD PLASMA PROFILES DURING A PERIOD OF HEIGH TRAINING LOADS AT ALTITUDE IN ELITE ATHLETES}

${ }^{1}$ Irina Zelenkova, ${ }^{2}$ Dmitriy Martinov, ${ }^{1}$ Sergey Zotkin, ${ }^{3}$ Elena Proskurnina. 'Zaragoza University, Zaragoza, Spain; ${ }^{2}$ Moscow State University, Faculty of basic medicine, Moscow, Russian Federation; ${ }^{3}$ Research Centre for Medical Genetics, Moscow, Russian Federation

\subsection{6/bjsports-2021-IOC.112}

Background Intensive muscular exercise is known to increase oxidative stress, free radical production and, as part of the physiological process of adaptations to adequate training loads.

Objective To evaluate the antioxidant reserve of blood plasma of elite athletes in the period of high training loads at altitude using a new approach based on kinetic chemiluminometry.

Design Prospective intervention study, without control group.

Setting Professional endurance athletes (speed skating).

Patients (or Participants) 13 elite athletes: 8 males (185 (180186) $\mathrm{cm}, 84(81-86) \mathrm{kg}$, body mass index $24.6(24.1-25.3)$ $\mathrm{kg} / \mathrm{m}^{2}, 26(24-27)$ yrs, VO2max $\left.60(61-67) \mathrm{mL} / \mathrm{min} / \mathrm{kg}\right)$ and 5 females $(164(164-171) \mathrm{cm}, 60(56-61) \mathrm{kg}$, body mass index $20.8(20.6-23.2) \mathrm{kg} / \mathrm{m}^{2}, 21(22-32)$ yrs, VO2max 57 (55-62) $\mathrm{mL} / \mathrm{min} / \mathrm{kg}$ ) participated in the study.

Interventions (or Assessment of Risk Factors) Athletes underwent training camp at the altitude $1850 \mathrm{~m}$ during 20 days. Blood was taken every four days in the morning on an empty stomach immediately after a day of rest.

Main Outcome Measurements Training impulse and hypoxic impulse were measured to quantify training and hypoxic dose. Measurement of the antioxidant activity of blood plasma by the derivative method of luminol-activated hemiluminescence using 2,2'-azobis (2-amidino-substituted) dihydrochloride (ABAP). The total antioxidant capacity (TAC) andantioxidant capacity by the required proteins were determined.

Results For each athlete a set of antioxidant profiles were obtained. A change in the antioxidant profile for both studied parameters were observed. The indicator that most quickly responds to training load - TAC. In female TAC had a smoother character, which may be associated with lower loads (TRIMP 190(108-242) c.u.in males and 131 (117-185)c.u. females) and/or «hypoxic dose» (M 98 (61104) c.u. and F $52(50-75)$ c.u.) or features of the adaptive response.

Conclusions The proposed technique can help in understanding antioxidant reserve of blood plasma and of elite athletes for future management. 